\title{
A Prospective comparative clinical study on the efficacy of stapler haemorrhoidopexy versus conventional haemorrhoidectomy in the management of haemorrhoids
}

\author{
Authors \\ Dr K.Vani ${ }^{1}$, Dr Chiguruvada Muni Ajitha ${ }^{2}$, Dr Konkena Janardhana Rao ${ }^{3}$ \\ Dr Yiza Ravindra Reddy ${ }^{4}$, Dr Ravi Theja Bathalapalli ${ }^{5}$, Dr K.Meghana ${ }^{6}$ \\ ${ }^{1,3}$ Associate Professor of Surgery, Government Medical College (RIMS), Kadapa, India \\ 2,5,6 Junior Resident of Surgery, Government Medical College (RIMS), Kadapa, India \\ ${ }^{4}$ Senior Resident of Surgery, Government Medical College (RIMS), Kadapa, India \\ *Corresponding Author \\ Dr Konkena Janardhana Rao \\ Associate Professor of Surgery, Government Medical College (RIMS), Kadapa, India
}

\begin{abstract}
Haemorrhoidal disease has been loathsome affliction of mankind. It is a painful condition to the sufferer and the treating surgeon. Several methods are available for the treatment of haemorrhoids ranging from the gold standard Milligan Morgan heamorrhoidectomy to the novel method of Stapler haemorrhoidopexy. With this background, a prospective comparative clinical study on the efficacy of stapler haemorrhoidopexy versus conventional haemorrhoidectomy in the management of haemorrhoids was conducted on 84 patients admitted in the Department of Surgery in a tertiary care hospital in the Rayalaseema districts of Andhra Pradesh from August, 2017 to March, 2019.

Conclusion: According to the results of our study, we consider Stapler hemorrhoidopexy as the preferred technique for the management of haemorrhoids given the appropriate conditions because of less post operative pain and morbidity than conventional techniques. However, because of the excessive cost of the stapler device, conventional hemorrhoidectomy remains the gold standard for the management of haemorrhoids in developing countries.
\end{abstract}

Keywords: Stapler, Hemorrhoidopexy, Conventional hemorrhoidectomy, Complications.

\section{Introduction}

Haemorrhoids are engorged venous plexuses of the anal canal and can cause prolapse, bleeding, pain, thrombosis and pruritus. Haemorrhoids are also known as piles and were known to human race since time immortal ${ }^{1}$. Hemorrhoids are one of the most common benign anorectal problems seen worldwide. The etiopathology is multifactorial and elusive including chronic constipation and chronic straining at stools. Ferguson and Heaton said, "Hundred percent of the population does suffer from hemorrhoids at least once in their lifetime $^{2}$. The role of surgery for treatment comes in grade III/IV hemorrhoids characterized as a symptomatic enlargement and distal displacement of the normal anal cushions ${ }^{3,4}$. Despite the major advances that have occurred in the treatment of colorectal diseases, there have been few 
modifications in the management of hemorrhoidal disease in the last decades. This is attributable to the fact that the mucosal incision and staple lines are positioned well above dentate line and the highly sensitive perianal skin is left intact ${ }^{5}$.

\section{Aim}

The aim of the study was to compare the duration of surgery, post operative bleeding, post operative pain, duration of hospital stay, time to return to work, and other complications in patients undergoing stapler haemorrhoidopexy versus open haemorrhoidectomy.

\section{Materials and Methods}

This study was conducted was on 84 patients admitted in the Department of Surgery in a tertiary care hospital in the Rayalaseema districts of Andhra Pradesh from August, 2017 to March, 2019. All the 84 patients were divided into two groups. 42 patients were included in each of the two groups of Stapler hemorrhoidopexy group
(SH group)

and

Conventional/Open hemorrhoidectomy group.

\section{Inclusion Criteria}

1. Patients admitted with symptomatic haemorrhoids (Refractory Grade 2, 3 \& 4).

\section{Exclusion Criteria}

1. Other concomittent anal disease.

2. Previous anal surgeries.

3. Hematological disorders.

4. Those unwilling for study.

\section{Methods of collection of data}

All the 84 patients who attended our hospital with grade 3, 4 and refractory grade 2 haemorrhoids were subjected to detailed clinical history, physical examination, routine blood investigations, proctoscopy and colonoscopy.

\section{Results}

A total of 84 patients in two equal groups were studied. Mean age of the two groups was similar. The two groups were comparable in age $[p=0.425]$. The gender distribution in both the groups was almost similar.

\section{Table: I}

\begin{tabular}{|c|c|c|c|c|c|c|}
\hline & \multicolumn{4}{|c|}{$\begin{array}{l}\text { Type of surgery } \\
\end{array}$} & \multirow{3}{*}{$\mathbf{T}$} & \multirow{3}{*}{$\mathbf{P}$} \\
\hline & \multicolumn{2}{|c|}{$\begin{array}{c}\text { Open } \\
\text { Haemorrhoidectomy }(\mathrm{N}=42)\end{array}$} & \multicolumn{2}{|c|}{$\begin{array}{c}\text { Stapler } \\
\text { Haemorrhoidopexy }(\mathrm{N}=42)\end{array}$} & & \\
\hline & Mean & Sd & mean & Sd & & \\
\hline $\begin{array}{l}\text { Duration of surgery } \\
\text { in minutes }\end{array}$ & 61.5 & 12.0 & 36.2 & 10.5 & 10.311 & $<0.001$ \\
\hline
\end{tabular}

Mean duration of surgery for open group is $61.5+12$ minutes and for stapler group is
$36.2+10.5$ minutes respectively, with statistical significance $[\mathrm{P}<0.001]$.

\section{Figure: I}

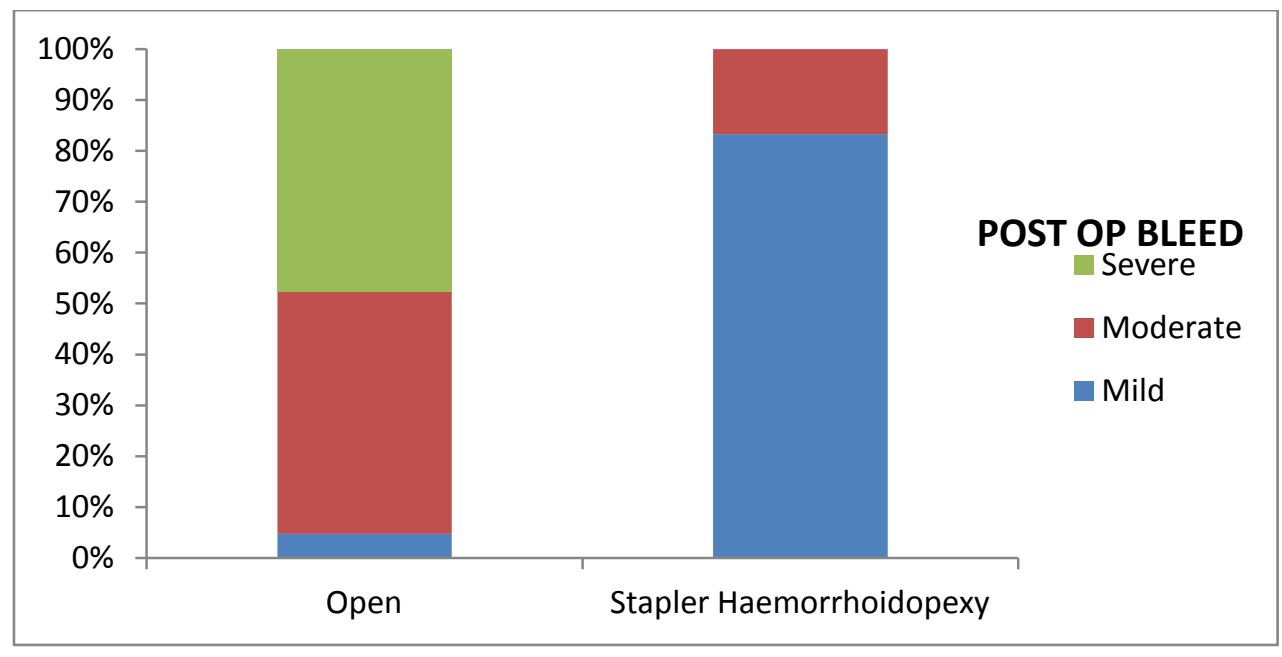


Moderate grade of bleeding was noticed in $48 \%$ in open group as compared to $17 \%$ in stapler group. Severe grade of bleeding was observed in $48 \%$ in open group as compared to $0 \%$ in stapler group.
Mild grade of bleeding was identified in $4 \%$ in open as compared to $83 \%$ in stapler group. This observation was statistically significant $[\mathrm{p}<0.001]$.

Figure: II

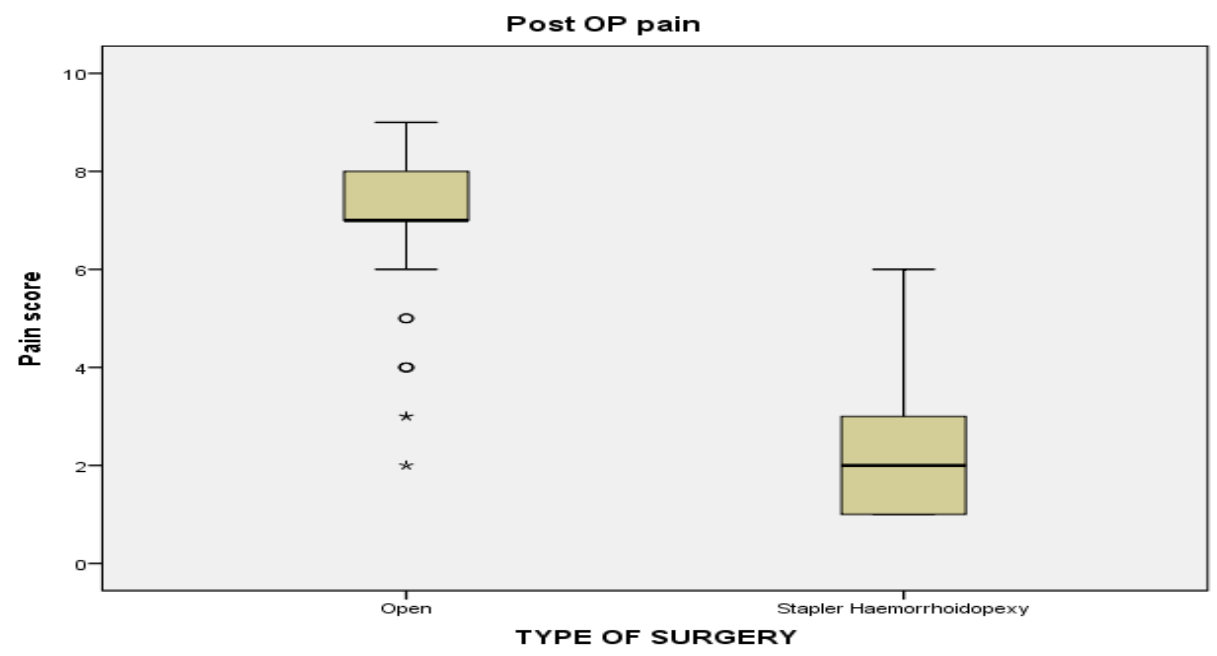

Pain in Post-operative period: Median of VAS scale for open group was 7 and for stapler group was 2 respectively with statistical significance [p $<0.001]$.
Pain on $10^{\text {th }}$ post-operative day: Median of VAS scale for open group was 1 and for stapler group was 0 respectively with statiscal significance $[P$ $<0.001]$.

\section{Figure: III}

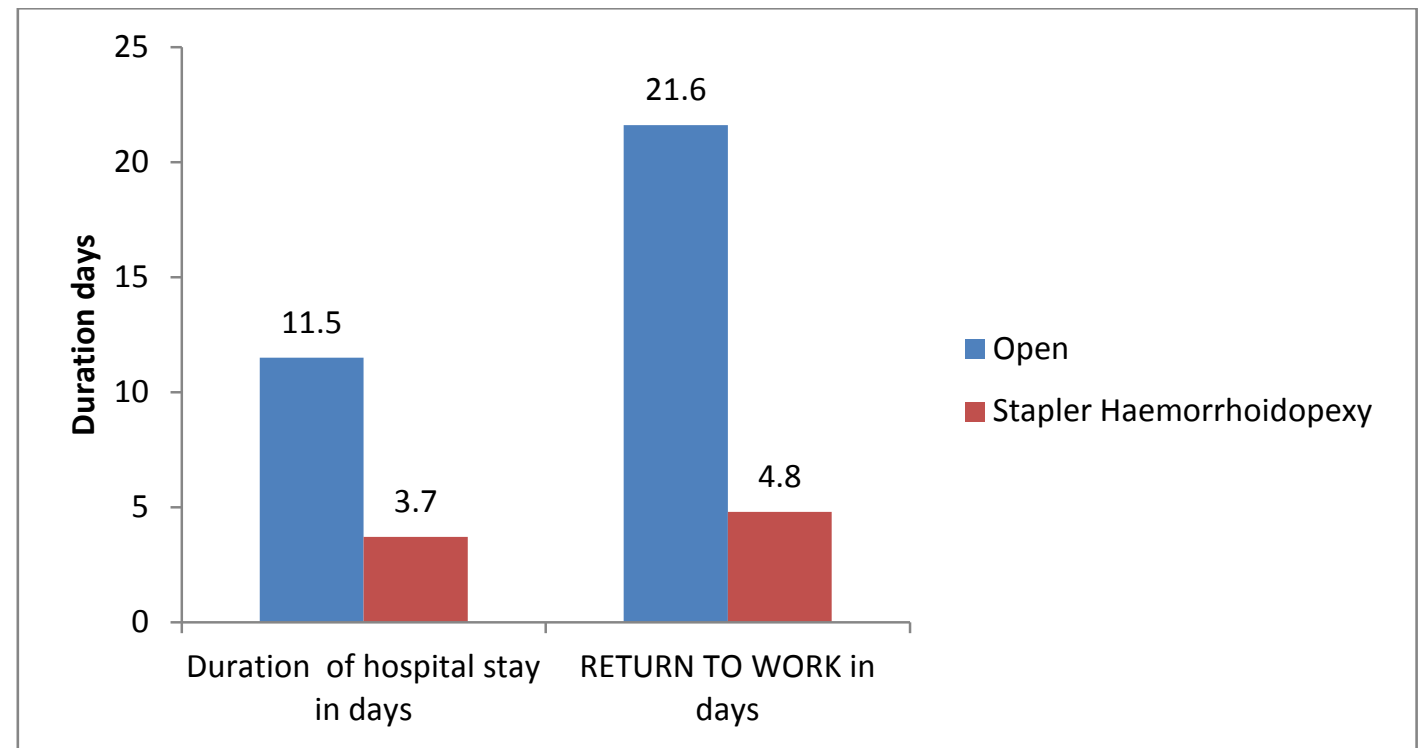

The mean duration of hospital stay for the open group was $11.5+1.9$ days and for the stapler group was $3.7+1.2$ days respectively, with statistical significance $[\mathrm{P}<0.001]$. The mean duration of return to work for the open group was $21.6+3.3$ days and for the stapler group was $4.8+1.2$ days respectively, with statiscal significance $[\mathrm{P}<0.001]$. 


\section{JMSCR Vol||07||Issue||05||Page 171-177||May}

Table : II

\begin{tabular}{|c|c|c|c|c|c|c|c|c|c|}
\hline & \multicolumn{4}{|c|}{ Type of surgery } & \multirow{2}{*}{\multicolumn{2}{|c|}{ Total }} & \multirow{3}{*}{$\chi^{2}$} & \multirow{3}{*}{ Df } & \multirow{3}{*}{$\mathrm{P}$} \\
\hline & \multicolumn{2}{|c|}{ Open Group } & \multicolumn{2}{|c|}{ Stapler Haemorrhoidopexy } & & & & & \\
\hline Post op infections & $\mathrm{N}$ & $\%$ & $\mathrm{~N}$ & $\%$ & $\mathrm{~N}$ & $\%$ & & & \\
\hline Absent & 30 & 71.4 & 37 & 88.1 & 67 & 79.8 & 3614 & 1 & 0,057 \\
\hline Present & 12 & 28.6 & 5 & 11.9 & 17 & 20.2 & 5.004 & 1 & 0.051 \\
\hline
\end{tabular}

Of the 42 patients in each group, 12 patients

$(29 \%)$ in open group and only 5 patients $(12 \%)$ in

stapler group had infection with statistical significance $[\mathrm{p}=0.05]$.

\section{Figure IV}

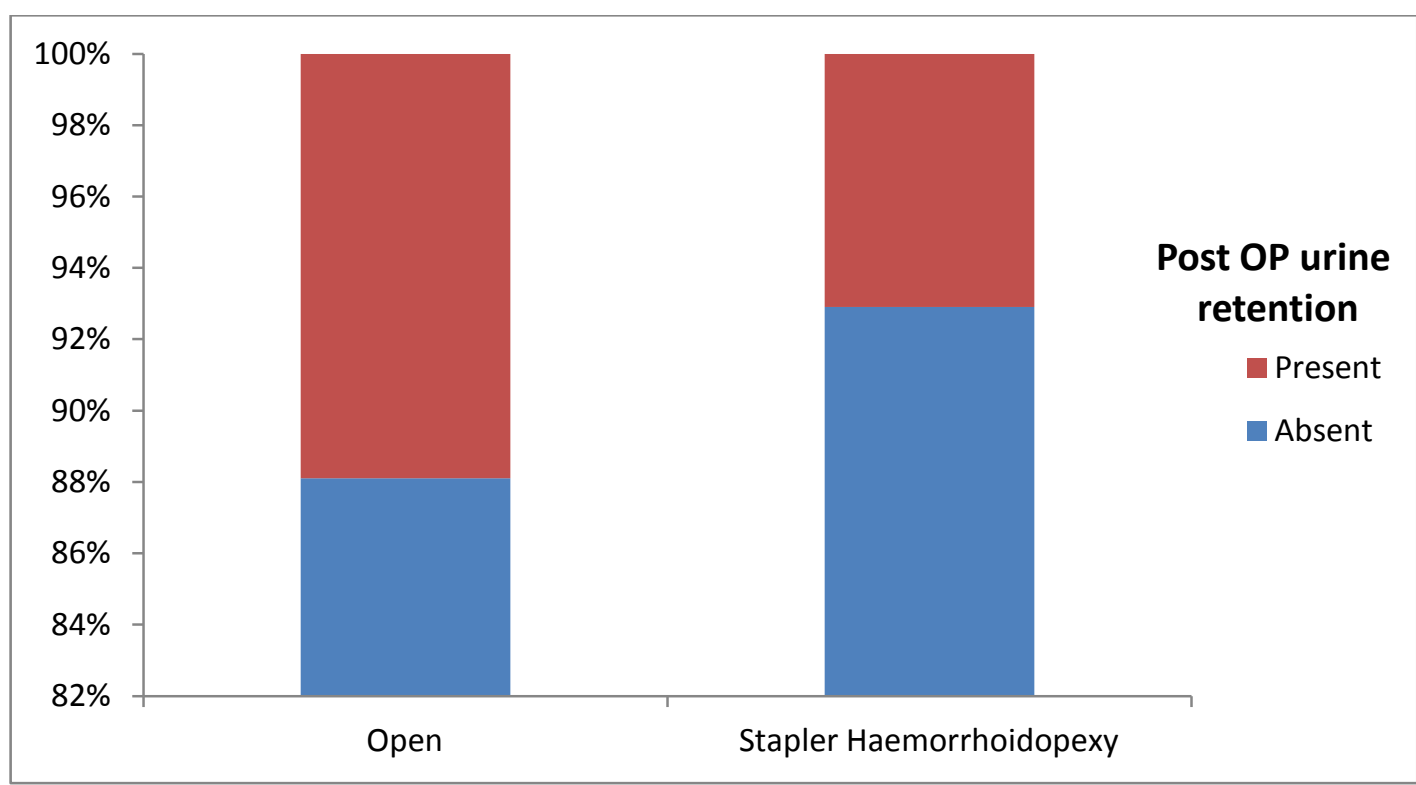

Of the 42 patients in the open haemorrhoidectomy group, 5 patients (12\%) had retention of urine. Of the 42 patients in the stapler haemorroidopexy group, only 3 patients (7\%) had retention of urine. However, when both the groups were compared there was no statistical significance [ $p=0.457]$.

\section{Discussion}

The very fact that there are a number of methods of management of haemorrhoids itself suggests that there is no optimal treatment for the same. This is the reason why better methods of management options evolve over time. One of the newer modalities of management of haemorrhoids is Stapler haemorrhoidopexy. With advances in our knowledge, the older techniques are replaced by newer horizons. In our study, we tried to compare stapler haemorrhoidopexy with the gold standard conventional haemorrhoidectomy.

\section{Duration of surgery}

The mean duration of surgery for conventional haemorrhoidectomy is $61.5+12$ minutes and for stapler haemorrhoidopexy is $36.2+10.5$ minutes respectively, with statistical significance $[P$ $<0.001]$. So the mean duration of surgery in conventional haemorrhoidectomy is significantly long. This is in comparision to a metaanalysis by Shao WJ et al from China and a study by Tjandra $\mathrm{JJ}$ et al from Melbourne who also observed shorter operating time in stapler haemorrhoidopexy compared to the conventional open haemorrhoidectomy ${ }^{6,7}$. Our results of lesser operating time for stapler haemorrhoidopexy was comparable to prospective study conducted by Shukla $\mathrm{S}$ et al from Bhopal, India who observed an average time of 36-40 minutes required for stapler haemorrrhoidopexy as compared to 41 - 45 minutes in conventional haemorrhoidectomy ${ }^{8}$. 


\section{Post operative bleeding}

Mild grade of bleeding was identified in $4 \%$ in open as compared to $83 \%$ in stapler group. Moderate grade of bleeding was noticed in $48 \%$ in open group as compared to $17 \%$ in stapler group. Severe grade of bleeding was observed in $48 \%$ in open group as compared to $0 \%$ in stapler group. This observation was statistically significant [p<0.001]. This was comparable to studies conducted by Shukla $\mathrm{S}$ et al from Bhopal, India and $\mathrm{N}$ aggarwal et al, from Dehradun, India, who also observed increased post operative bleeding in open haemorrhoidectomy compared to staplerhaemorrhoidopexy ${ }^{8,9}$.

\section{Post operative pain}

The VAS (visual analogue scale) score of immediate post operative pain in our study was 7 for open haemorrhoidectomy and 2 for stapler haemorrhoidopexy. During the follow up, majority of patients of open haemorrhoidectomy group complained of mild to moderate post operative pain where as very few patients of stapler haemorrhoidopexy group had mild pain. These results were similar to a study conducted by Rakhonde A et al from Bhopal, India and a metanalysis done by Chen JS et al from Taiwan, who also showed similar results regarding early post operative pain $^{10,11}$.

\section{Duration of hospital stay}

The mean duration of hospital stay for the open group was $11.5+1.9$ days and for the stapler group was $3.7+1.2$ days respectively. So the average duration of hospital stay in the open group was 12 days in comparison to 4 days in patients with stapler haemorrhoidopexy. The average hospital stay for open haemorrhoidectomy in our study was quite long when compared to several studies whose average ranged from 3-6 days. However, the average hospital stay for stapler haemorrhoidopexy was significantly less when compared to conventional haemorrhoidectomy. This is similar to the observations made by Shao WJ et al from China,
Shukla S et al from Bhopal, India and Gravie JF et al from France ${ }^{6,8,12}$.

\section{Return to normal work}

The mean duration of return to work for the open group was 21.6+3.3 days and for the stapler group was $4.8+1.2$ days respectively. On comparing the difference of duration of time to return to normal work between the stapler haemorrhoidopexy group and conventional haemorrhoidectomy group was found to be statistically significant. Singh SP et al observed that the median duration of time to return to normal work was 2 days in stapler group and 7 days in the conventional open surgery group ${ }^{13}$. Sachin et al in their study found that the mean duration of time to return to normal work was 8 days in the stapled group and 15 days in the open group ${ }^{14}$. However, the above results were in contrast to Ortiz et al who reported that there was no statistical significance in the mean time to return to work between the two groups ${ }^{15}$.

\section{Other complications}

One of the frequent complications that we encountered in the postoperative period was urinary retention. It was seen in 5 patients in the open haemorrhoidectomy group and 3 patients in the stapler haemorroidopexy group. However, when both the groups were compared there was no statistical significance $[\mathrm{p}=0.457]$. These observations were similar to those of Baliga $\mathrm{K}$ et $\mathrm{al}^{16}$. Other complications described in literature after stapler haemorrhoidopexy are a case of retroperitoneal sepsis by Molloy and Kingsmore, a case of rectovaginal fistula by Pescatori , 2 cases of rectal perforation by Cipriani $\mathrm{S}$ et al and acute intestinal obstruction due closure of rectum by purse string suture. However, we did not encounter these complications in our study. The above complications are probably because of inadequate experience and can be avoided by undergoing adequate training in stapler haemorrhoidopexy before contemplating this surgery $^{17,18,19}$. 


\section{Conclusion}

Haemorrhoids are a very common anorectal condition. There are different methods for the management of haemorrhoids. Conventional or open haemorrhoidectomy is a relativey safe, economical and highly effective procedure for the management of haemorrhoids. Stapler haemorrhoidopexy is associated with less post operative pain, less post operative bleeding and early return to work and is not associated with greater morbidity, which is associated with open haemorrhoidectomy. Stapler haemorrhoidopexy is reproducible and surgeons can achieve reasonable outcomes provided certain principles of surgery are followed and they have a minimum of experience. Hence, Stapler haemorrhoidopexy may be considered as the preferred technique for the management of haemorrhoids given the appropriate conditions. However, it is difficult to recommend stapler haemorrhoidopexy as a procedure of choice for all patients in a country like India in view of economic considerations as stapler devices are expensive.

\section{References}

1. Lan P, Wu X, Zhou X, Wang J, Zhang L. The safety and efficacy of stapled hemorrhoidectomy in the treatment of hemorrhoids: a systematic review and meta-analysis of ten randomized control trials. International journal of colorectal disease. 2006 Mar 1;21(2):172-8.

2. Ferguson JA, Heaton JR. Closed hemorrhoidectomy. Diseases of the Colon \& Rectum. 1959 Mar 1;2[2]:176-9

3. Longo A. Treatment of Hemorrhoids Disease by Reduction of Mucosa and Hemorrhoidal Prolapse with a Circular stapler Suturing Device: A New Procedure. In Proceeding of the 6th World Congress of Endoscopic Surgery 1998 [pp. 777-784.]

4. Ho YH, Cheong WK, Tsang C, Ho J, Eu KW, Tang CL, et al. Stapled Hemorrhoidectomy- cost and effectiveness. Randomized, controlled trial including incontinence Scoring, anorectal manometry, and endoanal ultrasound assessments at up to Three Months. Diseases of the colon \& rectum. 2000 Dec 31;43[12]:1666-75.

5. Smyth EF, Baker RP, Wilken BJ, Hartley JE, White TJ, Monson JR. Stapled versus excision haemorrhoidectomy: long-term follow up of a randomised controlled trial. The Lancet. 2003 Apr 26;361(9367): 1437

6. Shao WJ, Li GC, Zhang ZH, Yang BL, Sun GD,Chen YQ. Systematic review and meta analysis of randomized controlled trials comparing stapledhaemorrhoidopexy with conventional haemorrhoidectomy. $\mathrm{Br}$ J Surg. 2008;95(2):147-60.

7. Tjandra JJ, Chan MK. Systematic review on the procedure for prolapse and haemorrhoids (stapledhaemorrhoidopexy). Dis Colon Rectum.2007; 50(6):878-92.

8. Shukla $\mathrm{S}$ et al. Comparison between conventional haemorrhoidectomy and stapler haemorrhoidopexy Int Surg J. 2016 May;3(2):614-620.

9. Aggarwal $\mathrm{N}$ et al.Stapled haemorrhoidopexy vs. penhaemorrhoidectomy: a comparative study Int Surg J. 2019 Apr;6(4):1259-1263.

10. Rakhonde A et al. Haemorrhoidectomy stapler versus conventional (open): our experience Int Surg J. 2016 May;3(2):729735.

11. Chen JS, You JF. Current status of surgical treatment for haemorrhoid systematic review andmeta-analysis. Chang Gung Med J. 2010;33(5):488-500.

12. Gravie JF, Lehur PA, Huten N, Papillon M, FantoliM, Descottes B, et al. Stapled Haemorrhoidopexy Versus Milligan Morgan Haemorrhoidectomy; AnnSurg. 2005;242(1):29-35.

13. Singh SP et al. Comparison between stapler hemorrhoidectomy and open 
hemorrhoidectomy in the management of grade III and IV hemorrhoids: Int Surg J. 2018 Jun;5(6):2069-2073.

14. Sachin ID, Muruganathan OP. Stapled hemorrhoidopexy versus open hemorrhoidectomy: a comparative study of short term results. Int Surg J. 2017;4:472816.

15. Ortiz H, Marzo J, Armenderiz P. Randomized Clinical tral of stapled haemorrhoidopexy versus conventional diatermy haemorrhoidectomy. Br J Surg. 2002;89:1376-81.

16. Baliga K et al. Stapler hemorrhoidectomy versus open hemorrhoidectomy, Int Surg J. 2016 Nov;3(4):1901-1905 .

17. Molloy RG, Kingsmore D. Lifethreatening pelvic sepsis after stapled hemorrhoidectomy. Lancet. 2000;355:810.

18. Pescatori M. Transanal stapled excision of rectal mucosal prolapse. Tech Coloproctol. 1997;1:96-8.

19. Cipriani S, Pescatori M. Acute rectal obstruction following PPH hemorrhoidectomy. Colorectal Disease. 2002;4:36770. 